This item was submitted to Loughborough's Research Repository by the author.

Items in Figshare are protected by copyright, with all rights reserved, unless otherwise indicated.

\title{
Effect of symmetric and asymmetric substitution on the optoelectronic properties of 9,10-dicyanoanthracene
}

PLEASE CITE THE PUBLISHED VERSION

https://doi.org/10.1039/c9me00040b

\section{PUBLISHER}

(c) Royal Society of Chemistry

\section{VERSION}

AM (Accepted Manuscript)

\section{PUBLISHER STATEMENT}

This paper was accepted for publication in the journal Molecular Systems Design \& Engineering and the definitive published version is available at https://doi.org/10.1039/c9me00040b.

\section{LICENCE}

CC BY-NC-ND 4.0

\section{REPOSITORY RECORD}

Glocklhofer, Florian, Arnulf Rosspeintner, Pakorn Pasitsuparoad, Simon Eder, Johannes Frohlich, Gonzalo Angulo, Eric Vauthey, and Felix Plasser. 2019. "Effect of Symmetric and Asymmetric Substitution on the Optoelectronic Properties of 9,10-dicyanoanthracene". Loughborough University. https://hdl.handle.net/2134/38060. 


\title{
Journal Name
}

\section{ARTICLE TYPE}

Cite this: DOI: $10.1039 / \mathbf{x x x x x x x x x x}$

\section{Effect of symmetric and asymmetric substitution on the optoelectronic properties of 9,10-dicyano- anthracene ${ }^{\dagger}$}

\author{
Florian Glöcklhofer, ${ }^{\star a, e} \neq$ Arnulf Rosspeintner, ${ }^{\star b} \neq$ Pakorn Pasitsuparoad ${ }^{c}{ }^{\circ}$ Simon Eder, ${ }^{a}$ \\ Johannes Fröhlich, ${ }^{a}$ Gonzalo Angulo, ${ }^{c}$ Eric Vauthey, ${ }^{b}$ and Felix Plasser ${ }^{* d}$
}

Received Date
Accepted Date

DOI: 10.1039/xxxxxxxxxx

www.rsc.org/journalname

\begin{abstract}
A set of substituted 9,10-dicyanoanthracenes (DCA) has been synthesized, their photophysical and electrochemical properties in liquid solution have been characterized and supplemented by high level ab initio quantum chemical calculations. Three different methoxy-group-containing substituents have been linked to the DCA core in a symmetric and asymmetric fashion to produce six different species with strong quadrupole and dipole moments, respectively. The major difference between the symmetrically and asymmetrically substituted species are the enhanced two-photon absorption intensities of the former. In most of the cases studied, the molecules show reasonably large optical transition probabilities. The fluorescence brightness of these substances makes them interesting objects for two-photon absorption applications. Additionally, all molecules can be both easily reduced and oxidized electrochemically and are therefore suitable for optoelectronic applications.
\end{abstract}

\section{Introduction}

Simple organic molecules, easy to synthesize and with a variety of interesting photophysical and electrochemical properties have a large potential for optoelectronic and imaging applications. These properties comprise high fluorescence brightness, long fluorescence lifetimes, small intersystem crossing yields, large one- (1P) and two-photon (2P) cross sections and reversible and not too high redox potentials in both directions. Introducing nitriles into polyaromatic hydrocarbons has usually two beneficial effects with respect to these properties: first, it often increases the fluorescence quantum yield and secondly it enhances the oxidative power of the species. This is indeed the case for 9,10-dicyanoanthracene (DCA). Besides many reports in which this compound has been used in fundamental research of electron transfer, ${ }^{1-9}$ it has been applied, for example, as a

\footnotetext{
a Institute of Applied Synthetic Chemistry, TU Wien, Getreidemarkt 9/163, 1060 Vienna, Austria. E-mail: f.glocklhofer@imperial.ac.uk

${ }^{b}$ Department of Physical Chemistry, University of Geneva, 30, Quai Ernest Ansermet, CH-1211 Geneva, Switzerland. E-mail: arnulf.rosspeintner@unige.ch

${ }^{c}$ Institute of Physical Chemistry, Polish Academy of Sciences, 01-224 Warsaw, Poland.

${ }^{d}$ Department of Chemistry, Loughborough University, LE11 3TU, United Kingdom.

${ }^{e}$ Department of Chemistry and Centre for Plastic Electronics, Imperial College London, London W12 OBZ, UK. E-mail: F.Plasser@lboro.ac.uk

$\dagger$ Electronic Supplementary Information (ESI) available: experimental methods; additional experimental data; molecular geometries, Q-Chem input and output files of the computations of 2P properties (zip). See DOI: 10.1039/b000000x/

$\$$ These authors contributed equally to this work.
}

photosensitizer ${ }^{10}$ for the oxidation of alkynes to diketones, ${ }^{11}$ for oxidative cyclization reactions, ${ }^{12}$ alkynylation of carboxylic acids, ${ }^{13}$ benzylic amination by cross dehydrogenative coupling, ${ }^{14}$ as well as for aromatic substitutions. ${ }^{15}$ Furthermore, DCA is a key (photo)catalyst in the synthesis of the antimalarial drug artemisinin. ${ }^{16}$

Attaching oxidizable substituents to an aromatic core of high oxidative power (particularly in the excited state), such as DCA, can lead to dramatic modifications of the properties through the enhancement of multipolar moments. It is in fact possible to increase either the dipolar or quadrupolar transition moments of a molecule by playing with the symmetry of the substitution. While the substituent effects on the electronic spectra of anthracene have been thoroughly investigated in the past ${ }^{17-20}$ it is only relatively recent, that donor-substituted DCA derivatives have raised the interest of researchers due to their interesting non-linear optical properties. ${ }^{21-23}$ The rather few examples, mostly cruciforms with amino substituted styryl substituents in the 2 and 6 position on DCA, all exhibit considerable red-shifts of the absorption and emission spectra, as well as significantly increased two-photon absorption cross-sections. On the other hand, 2,6-donor substituted derivatives of anthraquinone $e^{24-26}$ and a heterocyclic homologue ${ }^{27}$ have attracted recent attention due to their delayed flourescence properties.

Some of us have recently developed a new synthetic method that allows for an easy derivatisation of DCA with electrondonating substituents in positions 2 and $6 .{ }^{28,29}$ Here, the choice 
<smiles>[Y2]c1ccc2c(C#N)c3cc([Y])ccc3c(C#N)c2c1</smiles>

DCA: $\mathrm{X}_{1}=\mathrm{X}_{2}=\mathrm{H}$

$\mathrm{R}_{1}$ : OMe
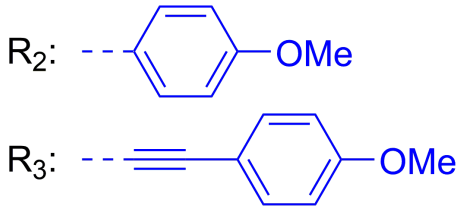

D1: $X_{1}=R_{1} X_{2}=H$

D2: $X_{1}=R_{2} X_{2}=H$

D3: $X_{1}=R_{3} X_{2}=H$

Q1: $X_{1}=X_{2}=R_{1}$

Q2: $X_{1}=X_{2}=R_{2}$

Q3: $X_{1}=X_{2}=R_{3}$

Chart 1 Molecular structures of 9,10-dicyanoanthracene (DCA) and its dipolar (D1-D3) and quadrupolar (Q1-Q3) methoxy-substituted derivatives.

of methoxy-functionalized substituents instead of other stronger electron donors is based on the prevention of lowering the fluorescence quantum yield and lifetime of the species too much. Too large a difference in the reduction potentials of the electron donating and accepting moieties would lead to large Stokes shifts, placing the emission in a region where the radiative rate decreases and the non-radiative rate increases.

In the present work we will provide all the details of the synthesis of six new such methoxy-substituted DCA-derivatives, their linear and non-linear photophysical properties and their electrochemical redox potentials in liquid solutions. One of the most interesting properties we have measured is the $2 \mathrm{P}$ absorption cross section and the associated spectra. The experimental data are supplemented by high-level $a b$ initio quantum mechanical calculations, which help rationalizing the observed differences among the species.

\section{Results and Discussion}

\subsection{Synthesis}

DCA is most commonly synthesized by replacing the bromides of 9,10-dibromoanthracene with cyanides in a so-called Rosenmund-von Braun reaction. ${ }^{30,31}$ However, this is not a feasible method for the synthesis of most substituted DCAs. Hence, we used a new cyanation method, which was recently introduced by some of us and which allows for the synthesis of both DCA and DCA derivatives from anthraquinones instead of dibromoanthracenes. ${ }^{28,29}$

For the target compounds D1 and Q1 (with methoxy groups directly attached to the DCA), the cyanation was the final step of the synthesis (Scheme 1). The required precursors $\mathbf{2} \mathbf{a}-\mathbf{b}$ were obtained by methylation of the respective hydroxyanthraquinones 1a-b. Although the new cyanation was previously demonstrated to proceed well also with functional groups attached to the anthraquinone, ${ }^{32}$ the electron-donating character of the methoxy groups of 2a-b initially impeded successful cyanation. Reduced temperatures and increased reaction times solved this issue.

In contrast to the synthesis of D1 and Q1, the synthesis of compounds D2, Q2, D3, and Q3 was carried out by palladium-

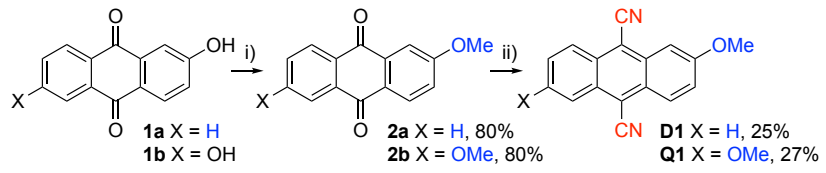

Scheme 1 Synthesis of methoxy-substituted DCAs D1 and Q1: (i) sodium hydride, iodomethane (2a) or $\mathrm{K}_{2} \mathrm{CO}_{3}$, dimethyl sulfate (2b); (ii) TMSCN, n-BuLi, $\mathrm{PBr}_{3}$. Yields are given as percentage.

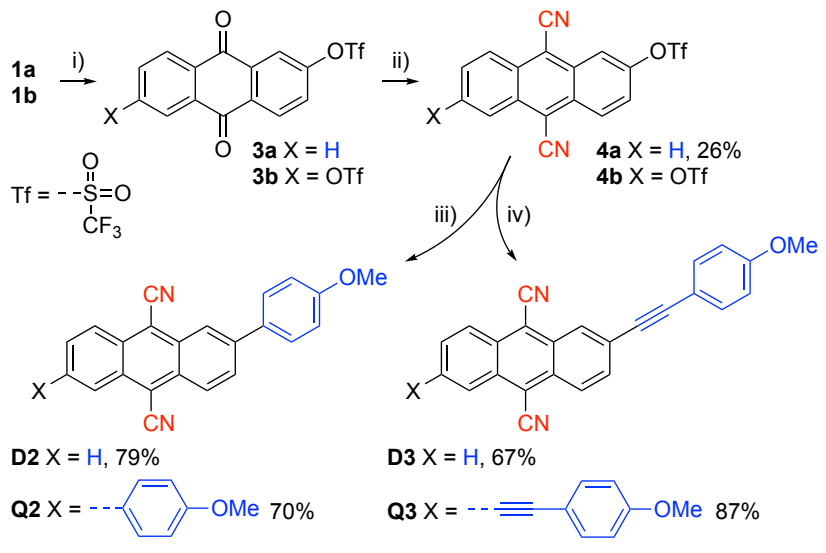

Scheme 2 Synthesis of 4-methoxyphenyl-substituted DCAs D2 and Q2 and (4-methoxyphenyl)ethynyl-substituted DCAs D3 and Q3: (i) pyridine, triflic anhydride; (ii) TMSCN, n-BuLi, $\mathrm{PBr}_{3}$; (iii) 4-methoxyphenylboronic acid, aq. $\mathrm{K}_{2} \mathrm{CO}_{3}, \mathrm{Pd}\left(\mathrm{PPh}_{3}\right)_{4}$, THF; (iv) 4-ethynylanisole, $\mathrm{PdCl}_{2}\left(\mathrm{PPh}_{3}\right)_{2}$, Cul, THF:diisopropylamine $(5: 1)$. Yields are given as percentage.

catalyzed coupling reactions as the final step (Scheme 2). Hydroxyanthraquinones $\mathbf{1} \mathbf{a}-\mathbf{b}$ were again used as the starting materials and were turned into anthraquinone triflates $\mathbf{3 a - b}$ first. DCA triflates $\mathbf{4 a - b}$ were then obtained by the new cyanation method and served as the coupling precursors. The triflates were selected as precursors, because DCA-triflate $\mathbf{4 b}$ was previously found to be more suitable for Suzuki coupling reactions than the respective halogenide. ${ }^{33}$ Thus, it came as little surprise that the Suzuki coupling reaction of $\mathbf{4 a - b}$ with 4-methoxyphenylboronic acid afforded target compounds D2 and Q2 in short reaction times and good yields; also the Sonogashira coupling reaction with 4-ethynylanisole towards target compounds D3 and Q3 worked very well under standard conditions.

A comprehensive description of the synthesis and basic characterization ( ${ }^{1} \mathrm{H}$ and ${ }^{13} \mathrm{C}$-NMR, high-resolution mass spectrometry) of all new compounds is given in the ESI.

\subsection{Electrochemistry}

Figure 1 summarizes the results of performing cyclovoltammograms (CV) in acetonitrile (see Fig. S1 and Table S2, as well as section 2.2 in the ESI for the experimental data and a description of the experimental method). Introduction of the two CN-groups in the 9 and 10 position in anthracene $(\mathbf{A})$ shifts both, reduction and oxidation potential to higher values by almost $1 \mathrm{~V}$, transforming the molecule from a relatively good photo-reductant to a good photo-oxidant, as judged by the estimated excited state redox po- 


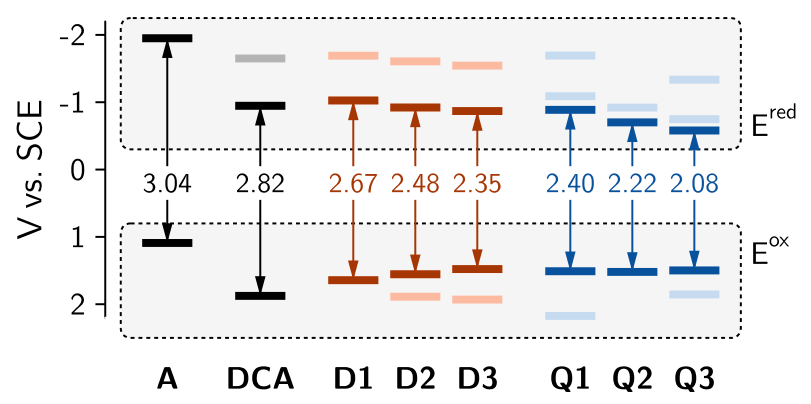

Fig. 1 Redox potentials (vs. SCE) in acetonitrile. Dark colors denote the first reduction and oxidation potential, while light colors denote additionally observed potentials. The numbers printed indicate the electrochemical band gap. For the cyclic voltammograms the reader is referred to the ESI.

tentials, $E^{*, \text { red/ox }}{ }^{34}$

$$
\begin{gathered}
E^{* \text {,ed }} \approx E^{\mathrm{red}}+E_{00} \\
E^{*, \mathrm{ox}} \approx E^{\mathrm{ox}}-E_{00}
\end{gathered}
$$

where $E_{00}$ is the energy of the first singlet excited state.

Asymmetric introduction of the donating methoxy-group derivative (in position 2) leads to a considerable reduction of the oxidation potential by up to $0.4 \mathrm{~V}$ (for D3) and an only insignificant increase of the reduction potential by up to $0.15 \mathrm{~V}$ compared to DCA. The symmetrically substituted compounds $(\mathbf{Q})$ all possess the same low-lying oxidation potential as D3, while the reduction potential is further enlarged with increasing side-group size up to a value of $-0.58 \mathrm{~V}$ for Q3. The shift in the redoxpotentials allows for the observation of additional oxidation and reduction potentials within the electrochemical window of acetonitrile. DCA and the D-series exhibit an additional (by $0.6 \mathrm{~V}$ more negative) reduction potential. For the $\mathbf{Q}$-series a total of three reduction potentials are found. In addition to those for the D-series an additional close-lying reduction potential at approx. $-0.2 \mathrm{~V}$ from the first one is observed. ${ }^{*}$ Similarly, additional higher lying oxidation potentials are found for some of the samples. However, no clear trends with the substitution pattern can be assigned.

In summary, increasing the molecular weight of the substituent in these series increases the oxidative as well as the reductive power of the substances in the electronic ground state. Dual substitution enhances this effect, and the overall change from DCA to Q3 amounts to +0.37 and $-0.38 \mathrm{~V}$ for the reduction and oxidation potentials, respectively. However, in their electronic excited state the redox properties change less due to the red shift of the emission spectra upon increasing the substituent's molecular weight (see eqs. (1)). * Note, that the assignment of the redox potentials for $\mathbf{Q} 2$ was complicated by its
limited solubility.

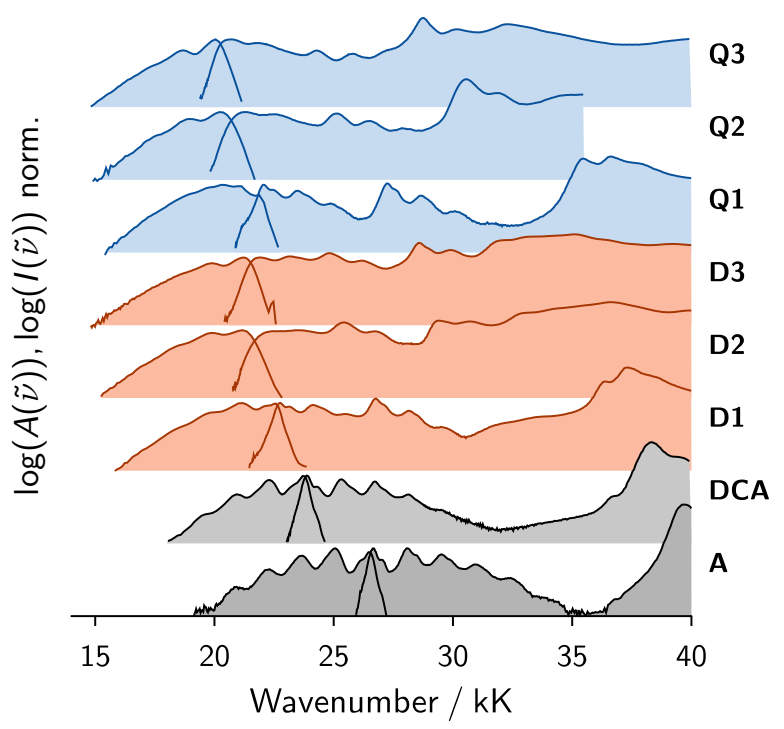

Fig. 2 Absorption and emission spectra in cyclohexane (vertically displaced, normalized to the lowest energy absorption band and on a logarithmic scale). For Q2 the excitation spectrum is shown, due to limited solubility. $1 \mathrm{kK}=1000 \mathrm{~cm}^{-1}$.

\subsection{Photophysical Properties}

In order to study the substituent-induced changes in the optical properties of DCA, steady-state absorption of one (1P) and two photons (2P) and fluorescence, as well as time-resolved emission experiments were performed in selected solvents of varying polarity (cf. Table S1 in the ESI). In addition, the involved excited states were modelled using high-level $a b$ initio theory employing the algebraic diagrammatic construction, $\operatorname{ADC}(2),{ }^{35,36}$ their $1 \mathrm{P}$ and $2 \mathrm{P}$ absorption properties were computed, ${ }^{37,38}$ and their wavefunctions were analysed in detail to gain insight into the electronic distribution in the excited states over the different parts of the molecule. ${ }^{39,40}$ A comprehensive collection of the experimental details and methods as well as additional results can be found in the ESI.

\subsubsection{One-Photon (1P) Absorption}

Figure 2 shows a compilation of the absorption and emission spectra in nonpolar cyclohexane of all 7 compounds, as well as those of the completely unsubstituted anthracene core (A). In combination with Figure 3, which shows the energy of the lowest energy absorption transition, as well as the corresponding transition dipole moment (defined in the ESI), various observations can be made.

Introduction of the cyano-groups in the 9,10-position in $\mathbf{A}$, yielding DCA, causes a significant red-shift of the lowest lying absorption band by $2.8 \mathrm{kK}$ and a smaller shift by only $1.4 \mathrm{kK}$ of the high energy band at $39.7 \mathrm{kK}$. In addition, the appearance of a weak new band in the range of $34-35 \mathrm{kK}$ can be observed. The significant red-shift of the $S_{1} \leftarrow S_{0}$ absorption band is accompanied by a distinct increase in the transition dipole moment, $M_{\mathrm{a}, 1}$, by more than $20 \%$ (cf. Fig. 3).

Decorating the DCA-core with the methoxy substituents in po- 


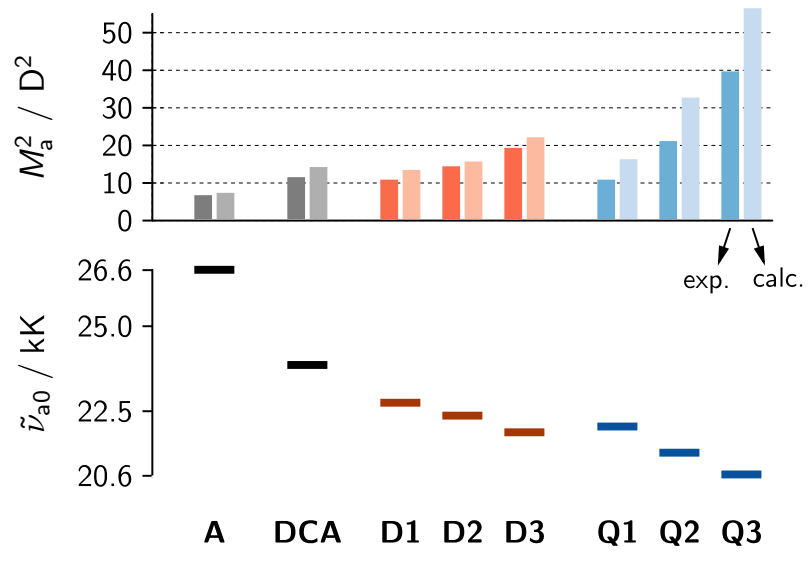

Fig. 3 Energy of the lowest lying absorption band in cyclohexane (lower panel) and the squared transition dipole moment (experimental - dark colors; calculated - light colors) of this transition (upper panel). For the extraction of the experimental values of $M_{\mathrm{a}}$ the reader is referred to the ESI.

sition 2 has multiple effects on the electronic absorption spectrum. First, the energy of the $S_{1} \leftarrow S_{0}$ transition decreases by 1.1 to $2.0 \mathrm{kK}$ with respect to that of DCA, when going from D1 to D3. Second, while the vibronic progression of this band - very pronounced in DCA - almost vanishes with increasing substituent size, its transition dipole moment steadily increases by up to $30 \%$ from 3.3 for D1 to 4.4 D for D3. Third, the entire absorption spectrum for the $\mathbf{D}$-series becomes more and more congested with new absorption bands showing up in the wavenumber range between the two clearly visible ones of $\mathbf{A}$ and DCA. In particular, the elusive second electronic transition in $\mathbf{A}$ at approx. $30 \mathrm{kK},{ }^{41}$ which for DCA is located at approx. $26.6 \mathrm{kK}$, though difficult to detect (can be intuited from the failing mirror symmetry relationship seen in Fig. S5 in the ESI), is fully appreciated at $26.7 \mathrm{kK}$ for D1 (see Fig. 2). This band corresponds to the transition to a state usually denoted as $L_{\mathrm{b}}$ or $B_{3 \mathrm{u}}^{-}$, which is pseudoparity forbidden in alternant hydrocarbons such as $\mathbf{A}$. As this symmetry is broken its intensity gradually increases when going from $\mathbf{A}$ to DCA to D1 and the computed transition dipole moments increase as 0.08 , 1.4, 2.2 D along this series.

The effect of introducing an additional identical substituent in position 6 on the DCA-core lowers the lowest energetic absorption transition by about $1 \mathrm{kK}$ compared to the $\mathbf{D}$-series. The second absorption band is equally visible as for the D-series, however it is significantly blue-shifted in Q1 compared to D1, while for Q3 it coincides with the position in D3. The most striking difference between $\mathbf{D}$ - and $\mathbf{Q}$-series resides in the distinct changes of the transition dipole moment, $M_{\mathrm{a}, 1}$, of the $\mathrm{S}_{1} \leftarrow \mathrm{S}_{0}$ absorption (cf. Fig. 3). While for D1/Q1 both $M_{\mathrm{a}, 1}$ are the same, that of $\mathbf{Q} 2$ is already $20 \%$ larger than that of D2. This trend culminates in $M_{\mathrm{a}, 1}$ of Q3 being more than 40\% larger than that of D3. The computed transition dipole moments (light bars in Fig. 3) reflect the experimental trends well and always stay within $20 \%$ of the experimental value, but are consistently larger.

Changes in the electrostatic properties of the solvent $(\varepsilon, n)$ have only minute effects on the absorption spectra of the studied samples (see Fig. S2 in the ESI). In particular, the electronic bands broaden as expected with increasing solvent polarity and exhibit only small to almost negligible (positive or negative) solvatochromism, which will be reported and discussed below.

\subsubsection{Excited State Properties}

All investigated samples show fluorescence, the spectral position, quantum yield and lifetime of which are strongly sample and solvent dependent.

Spectral Position and Mirror Symmetry. A and DCA show fluorescence spectra with pronounced vibronic structure and a small, though distinct, solvatobathochromism (cf. Fig. S2). A closer look (cf. Fig. S5) reveals, that for $\mathbf{A}$ an almost perfect mirror symmetry between absorption and fluorescence is observed. In the case of DCA significant deviations from this mirror symmetry are observed commencing with the $0-2$ vibronic transition at $26.6 \mathrm{kK}$ in absorption. This is owed to the overlapping distinct absorption to the $\mathrm{S}_{2}$-state of DCA.

In apolar solvents the emission spectra of the $\mathbf{D}$ - and $\mathbf{Q}$-series show a very small Stokes shift and exhibit vibronic structure, which only for $\mathbf{D 2 / Q 2}$ results in mirror symmetry with the absorption spectrum (see Fig. S6). For D1/Q1 the mirror symmetry is severely hampered by what could be the result of two spectrally overlapping emission bands (vide supra). In the case of D3/Q3 the emission spectra are slightly narrower than the corresponding absorption transition with a slightly less pronounced vibronic progression. This may be indicative of slight differences in torsional disorder between the ground and excited state. However apart of this, the mirror symmetry relationship, indicative of little differences in the nuclear configuration between absorbing and emissive state, holds rather well. ${ }^{43}$

When the solvent polarity is varied from cyclohexane (CX) to propylene carbonate (PC), all samples of the $\mathbf{D}$ - and the $\mathbf{Q}$-series show solvatobathochromism, which extends from less than $1.5 \mathrm{kK}$ for $\mathbf{D 1} / \mathbf{Q} 1$ to up to $6-7 \mathrm{kK}$ for $\mathbf{D} 3 / \mathbf{Q} 3$. These solvent shifts are accompanied by a complete loss of vibronic structure.

Radiative and Non-radiative Deactivation. In order to obtain insight into the excited state deactivation channels we measured fluorescence quantum yields, $\phi_{\mathrm{f}}$, and lifetimes, $\tau_{\mathrm{f}}$, which are summarized in Table 1 (also Tables S4 to S6). All samples with the exception of D1 and Q1 show monoexponential fluorescence decays on the nanosecond timescale over the entire emission spectrum. The latter two show biexponential decays, with the two lifetimes exhibiting a wavelength and amplitude dependence indicative of a precursor-successor kinetic scheme. In both samples the signal decays biphasically in the blue part of the emission spectrum, while in the red part the signal grows in with the shorter lifetime. Especially for D1 the assignment of the lifetimes is difficult as the two lifetimes are similar. In general the fluorescence quantum yields are intermediate to very high, with the fluorescence lifetimes ranging from a few ns up to slightly less than $20 \mathrm{~ns}$.

Rather than using $\phi_{\mathrm{f}}$ and $\tau_{\mathrm{f}}$ as representative quantities, we opt 
Table 1 Basic photophysical properties of all samples (in all solvents) at $20^{\circ} \mathrm{C} .1 \mathrm{kK}=1000 \mathrm{~cm}^{-1}$

\begin{tabular}{|c|c|c|c|c|c|c|c|c|}
\hline sample & solvent $^{\mathrm{a}}$ & $\begin{array}{c}\varepsilon \\
{\left[\mathrm{M}^{-1} \mathrm{~cm}^{-1}\right]}\end{array}$ & $\phi_{\mathrm{f}}$ & $\begin{array}{c}\tau_{\mathrm{f}} \\
{[\mathrm{ns}]}\end{array}$ & $\begin{array}{l}\tilde{v}_{\mathrm{aa}}^{\mathrm{b}} \\
{[\mathrm{kK}]}\end{array}$ & $\begin{array}{c}\tilde{v}_{\mathrm{f}}^{\mathrm{c}} \\
{[\mathrm{kK}]}\end{array}$ & $\begin{array}{l}M_{\mathrm{a}, 1} \\
{[\mathrm{D}]}\end{array}$ & $\begin{array}{l}M_{\mathrm{f}} \\
{[\mathrm{D}]}\end{array}$ \\
\hline$A^{d}$ & c-Hex & 9800 (@356nm) & 0.32 & 4.9 & 26.66 & 26.49 & 2.8 & 2.6 \\
\hline DCA & $\begin{array}{l}\mathrm{c}-\mathrm{Hex} \\
\mathrm{n}-\mathrm{Bu}_{2} \mathrm{O} \\
\mathrm{THF} \\
\text { PC }\end{array}$ & 14200 (@ 423 nm) & $\begin{array}{l}0.95 \\
0.87 \\
0.78 \\
0.94 \\
\end{array}$ & $\begin{array}{l}11.5 \\
12.0 \\
11.5 \\
13.3\end{array}$ & $\begin{array}{l}23.86 \\
23.81 \\
23.61 \\
23.53\end{array}$ & $\begin{array}{l}23.75 \\
23.53 \\
23.15 \\
22.94\end{array}$ & 3.4 & $\begin{array}{l}3.4 \\
3.3 \\
3.2 \\
3.3\end{array}$ \\
\hline$\overline{\mathrm{D} 1}$ & $\begin{array}{l}\mathrm{c}-\mathrm{Hex} \\
\mathrm{n}-\mathrm{Bu}_{2} \mathrm{O} \\
\mathrm{THF} \\
\text { PC }\end{array}$ & 13800 (@377nm) & $\begin{array}{l}1.00 \\
0.96 \\
0.87 \\
0.93\end{array}$ & $\begin{array}{l}16.2^{\mathrm{e}} \\
18.7 \\
18.0 \\
18.1\end{array}$ & $\begin{array}{l}22.75 \\
22.73 \\
22.60 \\
22.55\end{array}$ & $\begin{array}{l}20.59 \\
20.21 \\
19.49 \\
19.14\end{array}$ & 3.3 & $\begin{array}{l}3.3 \\
3.1 \\
3.2 \\
3.3\end{array}$ \\
\hline D2 & $\begin{array}{l}\text { c-Hex } \\
\text { n-Bu }{ }_{2} \mathrm{O} \\
\text { THF } \\
\text { PC }\end{array}$ & 16100 (@398nm) & $\begin{array}{l}0.36 \\
0.50 \\
0.76 \\
0.47\end{array}$ & $\begin{array}{r}5.1 \\
7.8 \\
12.6 \\
8.9\end{array}$ & $\begin{array}{l}22.37 \\
22.37 \\
22.37 \\
22.37\end{array}$ & $\begin{array}{l}19.66 \\
18.81 \\
16.94 \\
15.40\end{array}$ & 3.8 & $\begin{array}{l}3.8 \\
3.9 \\
4.3 \\
4.6\end{array}$ \\
\hline D3 & $\begin{array}{l}\mathrm{c}-\mathrm{Hex} \\
\mathrm{n}-\mathrm{Bu}_{2} \mathrm{O} \\
\mathrm{THF} \\
\mathrm{PC}\end{array}$ & 17400 (@407nm) & $\begin{array}{l}0.68 \\
0.53 \\
0.57 \\
0.05\end{array}$ & $\begin{array}{l}7.0 \\
5.7 \\
7.2 \\
0.7\end{array}$ & $\begin{array}{l}21.88 \\
22.00 \\
22.15 \\
22.30\end{array}$ & $\begin{array}{l}19.66 \\
18.55 \\
15.97 \\
13.42\end{array}$ & 4.4 & $\begin{array}{l}4.4 \\
4.8 \\
5.3 \\
6.1\end{array}$ \\
\hline$\overline{\text { Q1 }}$ & $\begin{array}{l}\text { c-Hex } \\
\text { n- } \mathrm{Bu}_{2} \mathrm{O} \\
\mathrm{THF} \\
\text { PC }\end{array}$ & 10400 (@458nm) & $\begin{array}{l}0.93 \\
0.96 \\
0.92 \\
0.94\end{array}$ & $\begin{array}{l}16.7^{\mathrm{e}} \\
17.9^{\mathrm{e}} \\
17.8^{\mathrm{e}} \\
18.7^{\mathrm{e}}\end{array}$ & $\begin{array}{l}22.05 \\
22.01 \\
21.84 \\
21.74\end{array}$ & $\begin{array}{l}19.71 \\
19.42 \\
18.91 \\
18.57\end{array}$ & 3.3 & $\begin{array}{l}3.3 \\
3.4 \\
3.5 \\
3.5\end{array}$ \\
\hline Q2 & $\begin{array}{l}\mathrm{c}-\mathrm{Hex} \\
\mathrm{n}-\mathrm{Bu}_{2} \mathrm{O} \\
\mathrm{THF} \\
\text { PC }\end{array}$ & 15000 (@474nm) & $\begin{array}{l}0.84 \\
0.94 \\
0.89 \\
0.77\end{array}$ & $\begin{array}{l}8.6 \\
8.9 \\
9.9 \\
8.9\end{array}$ & $\begin{array}{l}21.28 \\
21.15 \\
21.01 \\
20.94\end{array}$ & $\begin{array}{l}19.07 \\
18.60 \\
17.43 \\
15.90\end{array}$ & 4.6 & $\begin{array}{l}4.6 \\
5.1 \\
5.1 \\
5.7\end{array}$ \\
\hline Q3 & $\begin{array}{l}\mathrm{c}-\mathrm{Hex} \\
\mathrm{n}-\mathrm{Bu}_{2} \mathrm{O} \\
\mathrm{THF} \\
\mathrm{PC}\end{array}$ & 28400 (@ 482 nm) & $\begin{array}{l}0.80 \\
0.78 \\
0.74 \\
0.06\end{array}$ & $\begin{array}{l}4.6 \\
5.1 \\
5.8 \\
0.6\end{array}$ & $\begin{array}{l}20.64 \\
20.64 \\
20.64 \\
20.64\end{array}$ & $\begin{array}{l}20.04 \\
19.34 \\
16.00 \\
13.19\end{array}$ & 6.3 & $\begin{array}{l}6.3 \\
6.3 \\
6.9 \\
6.6\end{array}$ \\
\hline
\end{tabular}

${ }^{\mathrm{a}}$ c-Hex... cyclohexane, $\mathrm{n}-\mathrm{Bu}_{2} \mathrm{O} \ldots$ di-n-butyl ether, THF. . tetrahydrofuran, PC. . propylene carbonate

${ }^{b}$ the lowest vibronic absorption transition ${ }^{c}$ the highest energetic vibronic transition (for $\mathbf{A}$ and DCA) or the center of mass (all other samples), $\tilde{v}_{\mathrm{f}}=\int \tilde{v} I(\tilde{v}) \mathrm{d} \tilde{v}$, with $I(\tilde{v})$ being the area normalized emission spectrum. $\quad{ }^{\mathrm{d}}$ taken from ref. $42 \quad$ e biexponential decay, see Tables S4 and S6 in the ESI for data. Here only the long lifetime is given.

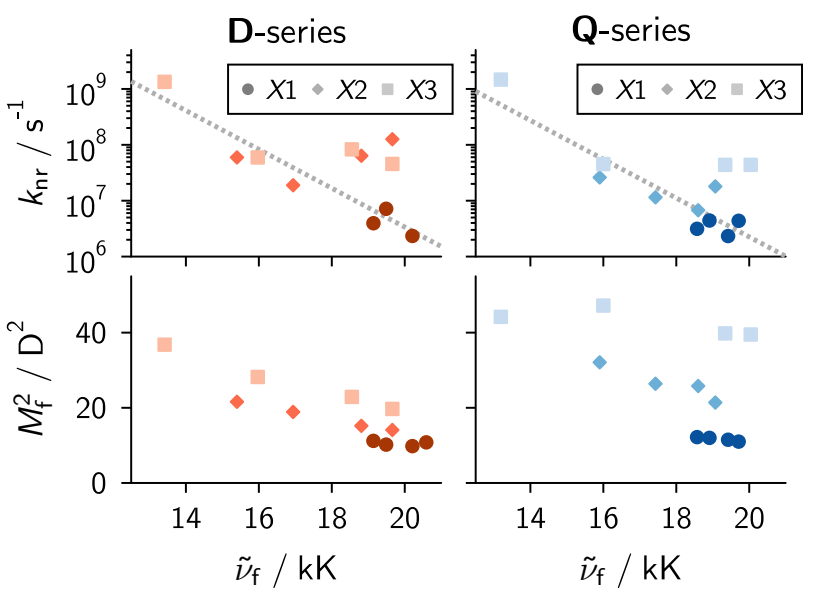

Fig. 4 Squared emission transition dipole moment, $M_{\mathrm{f}}^{2}$, (bottom panels) and non-radiative rate constant, $k_{\mathrm{nr}}$, (top panels) for the $\mathbf{D}$ - and $\mathbf{Q}$-series as a function of the first moment of the fluorescence band, $\tilde{v}_{f}$, in the same 4 solvents as in Table 1. The dashed lines are drawn to indicate a tentative free-energy gap dependence for the $S_{0} \leftarrow S_{1}$ internal conversion.

for the emission transition dipole moment, $M_{\mathrm{f}}{ }^{\dagger}$ and the rate of

$\dagger$ It is preferred to use $M_{\mathrm{f}}$ rather than the radiative rate constant, $k_{\mathrm{r}}$, as the latter has This journal is (c) The Royal Society of Chemistry [year] non-radiative deactivation, $k_{\mathrm{nr}}$. These two quantities are more straightforwardly interpreted and can be easily obtained from experiment (see eqs. (S3b) and (S4)).

Figure 4 summarizes the squared emission transition dipole moments and the non-radiative rate constants as a function of $\tilde{v}_{\mathrm{f}}$, as tabulated in Table 1. DCA, as well as D1 and Q1 show no solvent-, and thus energy gap-dependence of the transition dipole moment as well as the non-radiative rate constant. In fact, these two parameters are, within experimental error, identical for D1 and Q1 and very close to that of DCA. The situation is different for D2, Q2 and D3, Q3. The $M_{\mathrm{f}}^{2}$ of D2, D3 and Q2 steadily increases (almost by a factor of 2) with decreasing $\tilde{v}_{f}$, while the variation of $\mathbf{Q} 3$ is almost negligible. The non-radiative rate constants, on the other hand, seem to follow a universal free-energy gap dependence for all samples. However, the data of D2, Q2 and D3, Q3 at low polarity clearly deviate from the tentatively drawn $\mathrm{S}_{1} \leftarrow \mathrm{S}_{0}$ free-energy gap dependence. This behavior is not unusual and points to the interference of an additional deactivation channel with a different free-energy dependence, such as e.g. intersystem crossing to a close-lying triplet state. ${ }^{45,46}$

intrinsic dependencies on the refractive index of the solvent and the wavenumber of the emission. ${ }^{44}$ 


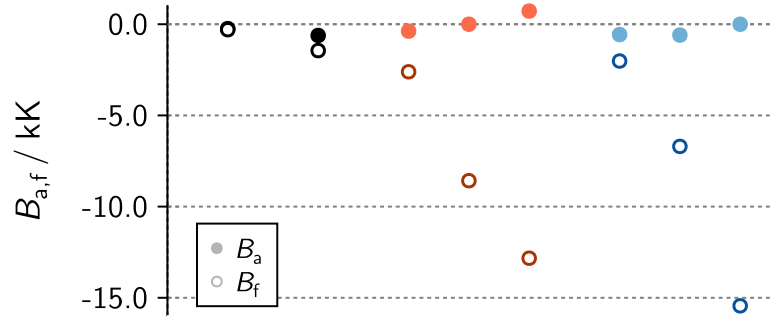

$\begin{array}{lllllllllllll}\text { A } & \text { DCA } & \text { D1 } & \text { D2 } & \text { D3 } & \text { Q1 } & \text { Q2 } & \text { Q3 }\end{array}$

Fig. 5 Slopes of the linear fits to the solvent polarity dependence of absorption (full circles) and emission (open circles) spectra using eq. (2).

\subsubsection{Solvatochromism}

Solvatochromism is very often used to investigate the changes in the electronic distribution of a given solute upon photoexcitation. A multitude of electrostatic effects are known to contribute to the energetic stabilization of the electronic states of said solute in a dielectric solvent continuum. ${ }^{47}$ Among these non-specific solutesolvent interactions all but one (solute electric multipole-solvent dipole) ${ }^{48}$ remain constant when investigating solvents of similar refractive index, $n$, and different dielectric constants, $\varepsilon$, (see Table $\mathrm{S} 1$ in the ESI) and can thus be subsumed in $A_{x}$ in eq. (2). The energy, $\tilde{v}_{x}$, for a given transition in a given solvent can now be expressed as

$$
\tilde{v}_{x}=A_{x}+B_{x} \cdot f(\varepsilon),
$$

where

$$
f(\varepsilon)=2 \cdot \frac{\varepsilon-1}{2 \varepsilon+1} .
$$

$x$ denotes either a(bsorption) or f(luorescence). $B_{x}$ can either be related to changes in the ground- and excited-state permanent dipole or quadrupole moment, thus resulting in the following expressions:

$$
\begin{aligned}
& B_{\mathrm{a}}=-\frac{\theta_{\mathrm{g}} \cdot\left(\theta_{\mathrm{e}}^{\mathrm{FC}}-\theta_{\mathrm{g}}\right)}{4 \pi \varepsilon_{0} a^{3} h c} \\
& B_{\mathrm{f}}=-\frac{\theta_{\mathrm{e}} \cdot\left(\theta_{\mathrm{e}}-\theta_{\mathrm{g}}^{\mathrm{FC}}\right)}{4 \pi \varepsilon_{0} a^{3} h c},
\end{aligned}
$$

where $\theta_{i}=\mu_{i}$ accounts for solvation of a permanent dipole and $\theta_{i}=Q_{i} / a$ for that of a quadrupole, subindices "e" and "g" refer to the corresponding quantities in the electronically excitedand ground state, FC denotes the Franck-Condon state and $a$ denotes the cavity radius. ${ }^{48}$ Fitting absorption and emission solvatochromism separately is to be preferred over the popular approach of fitting the Stokes shift, i.e. $\tilde{v}_{\mathrm{a}}-\tilde{v}_{\mathrm{f}}$, as it allows insight into whether the excited state energetics of the molecular system under investigation involve a simple two-level or three-level scheme. The results for all individual fits are compiled in Figure 5 (see also Table S3 and Fig. S4 in the ESI).

For all 7 systems the absorption solvatochromism of the lowestenergy absorption transition is perfectly well described by the above simplified model. The difference between fit and experiments is at most $50 \mathrm{~cm}^{-1}$ (see Fig. S4), which is clearly within the experimental uncertainty of the measurements. It has been put forward in the literature that the solvatochromism of DCA is due to solute quadrupole - solvent dipole interactions. ${ }^{48}$ Given the symmetry of the $\mathbf{Q}$-series it is thinkable that the same mechanism is operative for these samples.

The trend of the solvatochromic slopes, $B_{x}$, with the size of the molecules can provide some additional information about the states involved in the two transitions. Considering the simplest case of a spherical cavity and centered point-dipoles, ${ }^{49}$ increasing the cavity radius one can expect either a constant value of the dipoles or their increase, depending on the nature of the states. Additionally, one can assume that in each of the transitions the excited state dipole moment is always larger than that of the ground state. We will also assume that these are collinear.

The absorption of the $\mathbf{D}$ molecules qualitatively follows the expected trend for the typical case of not too large dipole moments, which smoothly increase with the size of the cavity. However, the $B_{\mathrm{a}}$ value for the $\mathbf{D} \mathbf{3}$ molecule is positive, meaning that the spectra show hypsochromism. It has been suggested that this is due to an eccentric localization of one of the permanent dipole moments, which would be compatible with a DCA localized transition. ${ }^{45,50}$ In other words, the absorption transition for the $\mathbf{D}$ molecules seems to be localized on the DCA-unit. The same trend is reflected in the computational data as discussed in more detail below.

The solvatochromism in emission is less straightforward (see the ESI for a quantitative rationale). The most common case would be to observe a decrease of the absolute value of $B_{\mathrm{f}}$ with increasing size of the cavity. This would be compatible with a concomitant linear increase of the permanent dipole moments of the states involved in this transition, as observed for the absorption. There are, nevertheless, other cases that could lead to the observed trends: if both permanent dipoles, i.e. that of the relaxed excited state and that of the FC ground state, increased their magnitude with the the cavity radius, the variation should be larger than linear if the nature of both states was similar (for example if both had a large CT character). If the FC ground state is of local character and its dipole moment does not increase with the size of the cavity it must be always rather large. However, this latter case is incompatible with the small dipole moment of the relaxed ground state. Therefore, it can be suggested that the FC-ground state has also CT character, just as the relaxed excited state. Such a situation would be also indicative of a structural change in the molecule during the relaxation of the excited state.

The trend in the solvatochromism of the absorption of the $\mathbf{Q}$ series is similar to that observed for the Ds, but with the dipole moments being replaced by quadrupolar moments. There is however a major difference in the fact that none of these $B_{\mathrm{a}} \mathrm{s}$ is positive, as to be expected for the higher symmetry of the Qs. The emission of the Qs, on the other hand, seems to be a copy of the trend observed for the Ds. Again, it would be possible to apply the same arguments as exposed above. However, it is suspicious that almost the exact same $B_{\mathrm{f}}$-values are observed. This suggests excited state symmetry breaking in the $\mathbf{Q}$-series upon relaxation of the excited state leading to a dipolar emissive state involving only one of the two substituents X. ${ }^{51,52}$ If so, then the effective 
cavity radius would be the same as in the $\mathbf{D}$-series, otherwise the $B$ s of the $\mathbf{Q}$-series should be smaller. In other words, the second substituent X (see Chart. 1) not only does not intervene in the electronic transition, it does not even contribute to an increase in the effective size of the cavity.

\subsubsection{Two-Photon (2P) Spectroscopy}

Figure 6 compares the $1 \mathrm{P}$ and $2 \mathrm{P}$ absorption spectra $\left(\varepsilon, \sigma^{2 \mathrm{P}}\right)$ recorded in THF.

The 2P absorption spectrum of DCA is red-shifted but otherwise similar to the one of anthracene and 9-methylanthracene published in ref. 53. Comparison of the absorption - fluorescence mirror symmetry (Fig. S5b) and the $2 \mathrm{P}$ absorption spectrum (Fig. 6) of DCA points towards the same interpretation: the pronounced $2 \mathrm{P}$ absorption at $28 \mathrm{kK}$ and the increased discrepancy in mirror symmetry starting at one vibronic transition lower, i.e. at $26.6 \mathrm{kK}$ indicate the presence and manifestation of the elusive second electronic excited state. In analogy to the observations in ref. 53 one can thus place the origin of this state at $26.6 \mathrm{kK}$.

The bandshape of the $2 \mathrm{P}$ spectra of the $\mathbf{D}$-series essentially resembles those of the 1P spectrum in the region of the lowest energetic electronic transition. The corresponding maximum $2 \mathrm{P}$ crosssection of this transition increases from 1.2 , over 17 to $37 \mathrm{GM}$. The second transition in $\mathbf{D} 1$ resembles the one observed for DCA with an identical change in vibronic structure (compared to the 1P spectrum), which for DCA and $\mathbf{A}$ had been assigned to a false origin of the vibronic progression. ${ }^{41}$ For D2 and D3, on the other hand, the vibronic pattern of the second transition is again quite similar to the 1P progression. Finally, D2 and D3 both exhibit a rather strong $2 \mathrm{P}$ absorption at 27 and $28 \mathrm{kK}$, respectively, with cross sections of 90 and $160 \mathrm{GM}$. This band coincides with the onset of the third electronic transition, which is clearly seen also in the 1P-spectra.

The 2P spectra of the $\mathbf{Q}$-series differ substantially, both from $\mathbf{A}$ and DCA as well as the D-series, in terms of bandshape and intensity. While Q1 still resembles the DCA 2P absorption spectrum, showing a similar bandshape and an only slightly larger intensity (maximum of 8 and only $0.3 \mathrm{GM}$ for the first electronic transition). In the case of $\mathbf{Q} 2$ and $\mathbf{Q} 3$ the 2P-extinction coefficient significantly increases to 13 and $40 \mathrm{GM}$ in the range of the first, and 260 to $430 \mathrm{GM}$ in the range of the second electronic transition. Additionally, the $2 \mathrm{P}$ spectra are void of any vibronic structure. In fact, the $1 \mathrm{P}$ and $2 \mathrm{P}$-spectra of $\mathbf{Q} \mathbf{2}$ and $\mathbf{Q} 3$ reproduce the often observed complementarity of strong (weak) 1P and weak (strong) 2P absorption bands, which is rooted in the mutually exclusive symmetry selection rules for centrosymmetric molecules. ${ }^{54}$ Here, however, the calculations (vide infra) clearly reveal, that the strong $2 \mathrm{P}$ absorption represents the $\mathrm{S}_{3} \leftarrow \mathrm{S}_{0}$ transition, while the weaker $1 \mathrm{P}$-absorbing $\mathrm{S}_{2} \leftarrow \mathrm{S}_{0}$ transition, just like the $\mathrm{S}_{1} \leftarrow \mathrm{S}_{0}$ transition, has no $2 \mathrm{P}$-strength.

Figure 6 also shows that the position and relative intensities of the main $1 \mathrm{P}$ and $2 \mathrm{P}$ absorption bands are well reproduced by computation. It is worth noting that the experimentally observable low energy shoulders in the $2 \mathrm{P}$ spectra of the $\mathbf{Q}$-series derive from the transition to the $S_{1}$ state, which is of ungerade symmetry and therefore 2 P-forbidden at the equilibrium geometry. The non- negligible intensity arises from vibronic coupling to the $S_{3}$ state. As a consequence, when attempting a quantitative comparison of experiment and calculations the full $2 \mathrm{P}$-absorption intensity has to be assigned to the computed $\mathrm{S}_{3} \leftarrow \mathrm{S}_{0}$ transition.

\subsection{Excited-state wavefunctions}

Finally, we want to investigate the excited state wavefunctions of the different molecules and how they lead to the varying photophysical properties observed (cf. to the ESI for a detailed description of the computational methods and collected results). For this purpose, we start with a discussion of the frontier orbitals of DCA and $\mathbf{Q 1}$ and proceed with a more compact and rigorous analysis of all the molecules studied.

In Figure 7 the frontier molecular orbitals (MOs) of DCA and Q1 are shown. Both, the HOMO and the LUMO possess strong contributions next to the electron-withdrawing CN group explaining why both their energies are lowered with respect to $\mathbf{A}$ upon substitution by CN (cf. Fig. 2). Accordingly, the oxidation and reduction potentials are raised (cf. Figure 1). The HOMO-2 is concentrated around positions 1, 4, 6 and 9 and possesses a similar shape to the HOMO albeit differing in its symmetry properties. The HOMO-1 has a distinct ladder-like shape and is located at the center of the molecule. Substitution at the 2 and 6 positions leading to Q1 only has a minor effect on the HOMO-1 and LUMO. By contrast, the breaking of the symmetry induced by the substituents is clearly visible for the HOMO and HOMO-2, which are moved toward the electron donating substituents.

The first three excited states of all centrosymmetric molecules (DCA, Q1, Q2, Q3) can, to a good approximation, be understood as excitations of an electron to the LUMO, starting from the HOMO, HOMO-1, and HOMO-2, respectively. Here, the HOMO/LUMO transition gives rise to $S_{1}$, which is the first bright state seen in the $1 \mathrm{P}$ absorption spectrum and derives from the $L_{\mathrm{a}}$ state of anthracene. The $\mathrm{S}_{2} \leftarrow \mathrm{S}_{0}$ transition is dominated by the HOMO-1/LUMO transition, with an additional contribution from the $\mathrm{HOMO} / \mathrm{LUMO}+1$ transition and can be understood to originate from the weakly allowed $L_{\mathrm{b}}$ state of anthracene. It gives rise to the weak second $1 \mathrm{P}$ band. The $\mathrm{S}_{3}$ state is of gerade symmetry and, therefore, not visible in the $1 \mathrm{P}$ spectrum. This state gives rise to the strong 2P band observed for all molecules of the $\mathbf{Q}$-series. In the case of the $\mathbf{D}$-series the symmetry is reduced, which allows for more complex interactions between the orbitals and the state characters cannot be assigned as readily.

A more compact analysis of all the excited states is given in Figure 8. First, we compare experimental and computational energy levels. A complete $a b$ initio determination of the band origins would require an excited-state geometry optimisation and frequency analysis, which is too expensive for the high computational level used here. Therefore, we have chosen a simpler route of red-shifting all calculated vertical excitation energies by $3 \mathrm{kK}$ to match the experimental results, noting that a redshift of this order of magnitude usually emerges when band origins are computed explicitly. ${ }^{55,56}$ These results are shown in the upper panel of Figure 8 along with the (estimated) experimental band origins. The results generally show good agreement whenever 

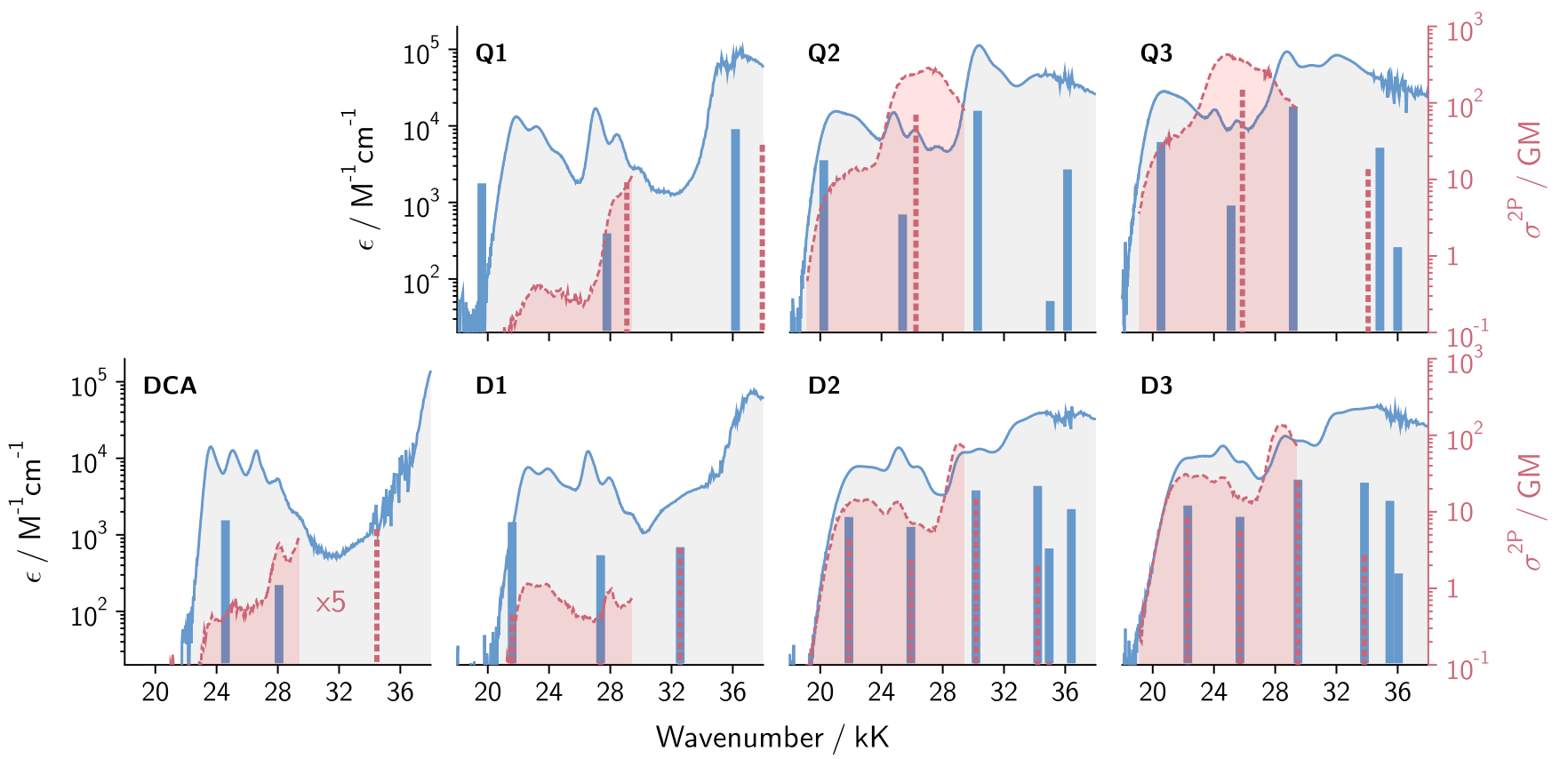

Fig. 6 One- $\left(\varepsilon\right.$, blue) and two-photon $\left(\sigma^{2 \mathrm{P}}\right.$, red) absorption spectra in tetrahydrofuran. The bars denote the calculated integrated one- and two-photonabsorption integrals for each transition (see eqs. (S6) and (S12) in the ESI), all scaled by a common scaling factor and red-shifted by $3 \mathrm{kK}$. The $\mathrm{x}$-axis for both sets of graphics denotes the energy of the electronic transition.

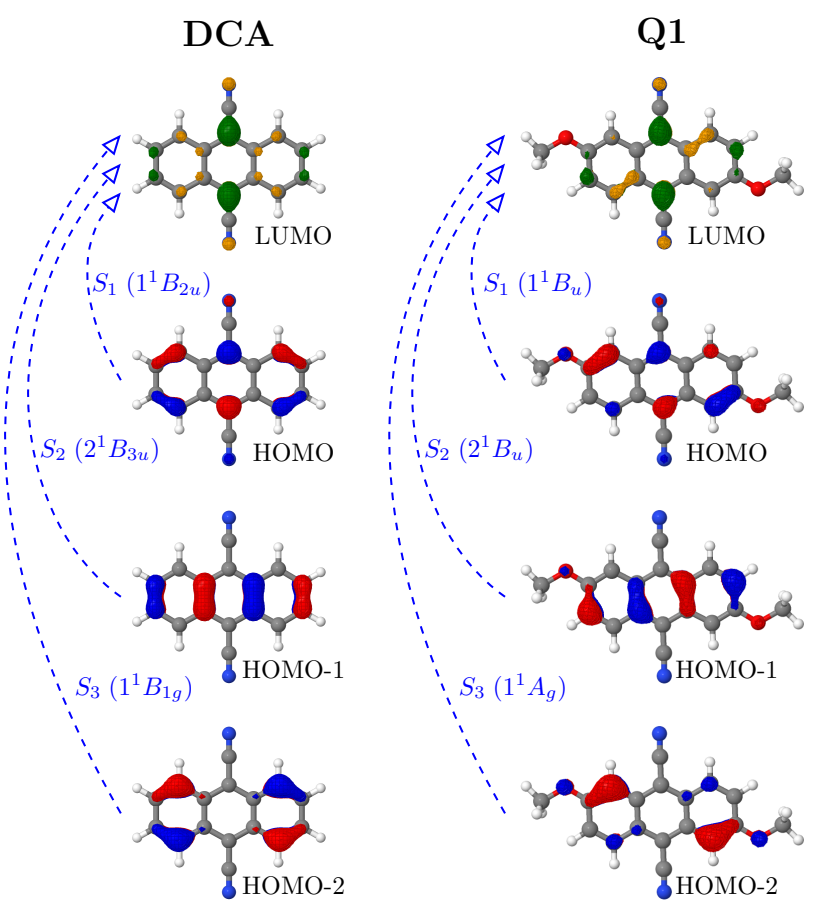

Fig. 7 Frontier orbitals of DCA and Q1 and dominant orbital transitions of their first three electronic transitions.

experimental reference values are available. The main exception is that experimental values of the lowest energy absorption band generally go down when going from $\mathbf{D 1 / Q 1}$ to $\mathbf{D} 3 / \mathbf{Q} 3$ while the computed values go up. Using the examples of D1 and D2, we have investigated whether this problem is specifically related to the ADC(2) level of theory. For this purpose, computations were performed at the more involved ADC(3) level ${ }^{57}$ leading to almost equivalent results. We are, therefore, left with the conclusion that the problem does not lie with ADC(2) but is probably a vibronic effect or related to the solvent. However, the important conclusion of Figure 8 (upper panel) is that all experimental bands can be uniquely identified with a computed electronic state allowing us to delve deeper into a discussion of these bands.

To assign the state characters of all the involved molecules in a compact and quantitative way, an analysis in terms of charge-transfer numbers was performed. ${ }^{39,40}$ For this purpose, the molecule was divided into three parts, the anthracene core (Ant), the CN groups and the substitutent (R), and the excitation was decomposed into local excitations on the individual fragments and charge transfer (CT) between them. This analysis is presented in the lower panel of Figure 8. Here, the colors of the bars correspond to the different local and CT characters and their size shows how much a specific character contributes to the overall state. It is observed that for the lower energy states, the dominant contributions are local excitations on anthracene ( $\square$ ) and $\mathrm{R} \rightarrow$ Ant CT character $(\square)$ while local character on $\mathrm{R}(\square)$ comes into play for some of the higher excited states. None of the lower lying states show an appreciable Ant $\rightarrow R$ contribution $(\square)$ or any type of involvement of the $\mathrm{CN}$ group $(\square)$. It is generally observed in Figure 8 that the transition to the $S_{2}$ states are mainly located on the anthracene unit, which is consistent with the fact that the HOMO-1 interacts only weakly with the substituent (cf. Figure 7). By contrast, the more strongly $1 \mathrm{P}$ and $2 \mathrm{P}$ absorbing $\mathrm{S}_{1} \leftarrow \mathrm{S}_{0}$ and $\mathrm{S}_{3} \leftarrow \mathrm{S}_{0}$ transitions show involvement of the substituent, which occurs to varying degrees. Here, it is interesting to note that there is a correlation between the CT character of the $\mathrm{S}_{1} \leftarrow \mathrm{S}_{0}$ 
transition and the transition moment as shown in Figure 3, where enhanced CT character leads to larger transition moments. In a similar sense, it is seen that the two transitions with the largest $2 \mathrm{P}$ absorption cross sections, i.e. the $\mathrm{S}_{3} \leftarrow \mathrm{S}_{0}$ transition of $\mathbf{Q} 2$ and Q3, are dominated by $\mathrm{R} \rightarrow$ Ant character. These findings illustrate the importance and the active involvement of the substituents. In the same sense, it is observed that the weight of local excitations on anthracene ( $\mathbf{\square}$ ) is higher for the $\mathbf{D}$-series when compared to the analogous $\mathbf{Q}$ molecules. This trend was also discussed in the context of solvatochromism, above.

\section{Conclusions}

Six new molecules were synthesized by attaching electron donating substituents to 9,10-dicyanoanthracene. Out of these molecules, D2, D3 and Q2, Q3 show favorable 2P properties with the best results for Q3. In all cases the fluorescence quantum yield is high in low polar environments, making these substances 2P-bright molecules. Moreover the maximum of the $2 \mathrm{P}$ absorption is close to $800 \mathrm{~nm}$, which makes it compatible with conventional Ti:sapphire femtosecond lasers.

Aside from enhancing the $2 \mathrm{P}$ absorption, the electron donating substituents were shown to decrease the electrochemical and optical band gaps following the trend $\mathbf{Q} \mathbf{3}<\mathbf{Q} \mathbf{2}<\mathbf{Q 1} \approx \mathbf{D} \mathbf{3}<\mathbf{D} \mathbf{2}<\mathbf{D} \mathbf{1}$. Of all the molecules studied Q3 has the lowest $S_{1}$ band origin and is the easiest to both oxidize and reduce. The substituents were also shown to enhance the transition dipole moments and strengthen the solvatochromism for fluorescence. Another interesting property of these molecules is the long lifetime of fluorescence, which they display in medium to low polar solvents.

A very good correlation between theory and experiment is obtained for the energy and intensity of the transitions, both for the one and for two photon transitions along the full spectra in all cases. Even the symmetry change in the $\mathbf{Q}$-series is well reproduced by the calculations. Both theory and experiments suggest an increasing role of the methoxy-containing substitutents with increasing its size in the transitions.

In summary, we have shown that rational addition of electron donating substituents to the DCA core, via straightforward synthetic methods, leads to substantial modifications in electrochemical and photophysical properties. Moreover, high level ab initio calculations are able to rationalize the observed experimental trends. This opens the possibility to explore other core and substituent groups for further improvement of the desired optoelectronic properties. In future works we will also explore the time dependent-behavior of the excited state of the here presented molecules.

\section{Acknowledgement}

The authors thank Emmanuel Reichsöllner, Andreas J. Morawietz and Markus Lunzer (TU Wien) for contributing to synthetic experiments. Brigitte Holzer and Christian Hametner (TU Wien) are acknowledged for NMR measurements, Jieyang Huang and Michael J. Bojdys (Charles University in Prague, Institute of Organic Chemistry and Biochemistry ASCR v.v.i.) for high-resolution mass spectrometry. Wojciech Nogala's (IChF-PAN, Warsaw) help with the electrochemical measurements is highly appreciated.
Financial support from the Narodowe Centrum Nauki (SONATA bis No. 2013/10/E/ST4/00534), the TU Wien, the University of Geneva and the Swiss National Science Foundation (Project No. 200020-165890) is acknowledged. We acknowledge the use of 'Athena' at HPC Midlands+, which was funded by the EPSRC on grant EP/P020232/1 as part of the HPC Midlands + consortium and the use of the 'Hydra' High Performance System at Loughborough University.

\section{References}

1 I. R. Gould, D. Ege, S. L. Mattes and S. Farid, J. Am. Chem. Soc., 1987, 109, 3794-3796.

2 I. R. Gould, D. Ege, J. E. Moser and S. Farid, J. Am. Chem. Soc., 1990, 112, 4290-4301.

3 I. R. Gould, R. H. Young, L. J. Mueller and S. Farid, J. Am. Chem. Soc, 1994, 116, 8176-8187.

4 M. Liang, A. Kaintz, G. A. Baker and M. Maroncelli, J. Phys. Chem. B, 2012, 116, 1370-1384.

5 A. Rosspeintner, G. Angulo and E. Vauthey, J. Phys. Chem. A, 2012, 116, 9473-9483.

6 M. Koch, A. Rosspeintner, K. Adamczyk, B. Lang, J. Dreyer, E. T. J. Nibbering and E. Vauthey, J. Am. Chem. Soc., 2013, 135, 9843-9848.

7 A. Rosspeintner, G. Angulo and E. Vauthey, J. Am. Chem. Soc., 2014, 136, 2026-2032.

8 B. Wu, M. Liang, M. Maroncelli and E. W. Castner, J. Phys. Chem. B, 2015, 119, 14790-14799.

9 B. Wu, M. Maroncelli and E. W. Castner, J. Am. Chem. Soc., 2017, 139, 14568-14585.

10 S. Blanc, T. Pigot, C. Cugnet, R. Brown and S. Lacombe, Phys. Chem. Chem. Phys., 2010, 12, 11280-11290.

11 H.-T. Qin, X. Xu and F. Liu, ChemCatChem, 2017, 9, 14091412.

12 J. L. Hofstra, B. R. Grassbaugh, Q. M. Tran, N. R. Armada and H. J. P. de Lijser, J. Org. Chem., 2015, 80, 256-265.

13 C. Yang, J.-D. Yang, Y.-H. Li, X. Li and J.-P. Cheng, J. Org. Chem., 2016, 81, 12357-12363.

14 G. Pandey and R. Laha, Angew. Chem. Int. Ed., 2015, 54, 14875-14879.

15 M. Neumeier, D. Sampedro, M. Májek, V. A. de la Peña O’Shea, A. Jacobi von Wangelin and R. Pérez-Ruiz, Chem. - Eur. J., 2018, 24, 105-108.

16 D. Kopetzki, F. Lévesque and P. H. Seeberger, Chem. - Eur. J., 2013, 19, 5450-5456.

17 R. N. Jones, Chem. Rev., 1947, 41, 353-371.

18 A. S. Cherkasov, Optics and Spectroscopy (U.S.S.R), 1959, 6, 315-318.

19 A. S. Cherkasov, Optics and Spectroscopy (U.S.S.R), 1959, 6, 496-502.

20 I. B. Berlman, Handbook of Fluorescence Spectra of Aromatic Molecules, New York: Academic Press Inc, 2nd edn., 1971.

21 W. J. Yang, D. Y. Kim, M.-Y. Jeong, H. M. Kim, S.-J. Jeon and B. R. Cho, Chem. Commun., 2003, 41, 2618.

22 W. J. Yang, D. Y. Kim, M.-Y. Jeong, H. M. Kim, Y. K. Lee, 


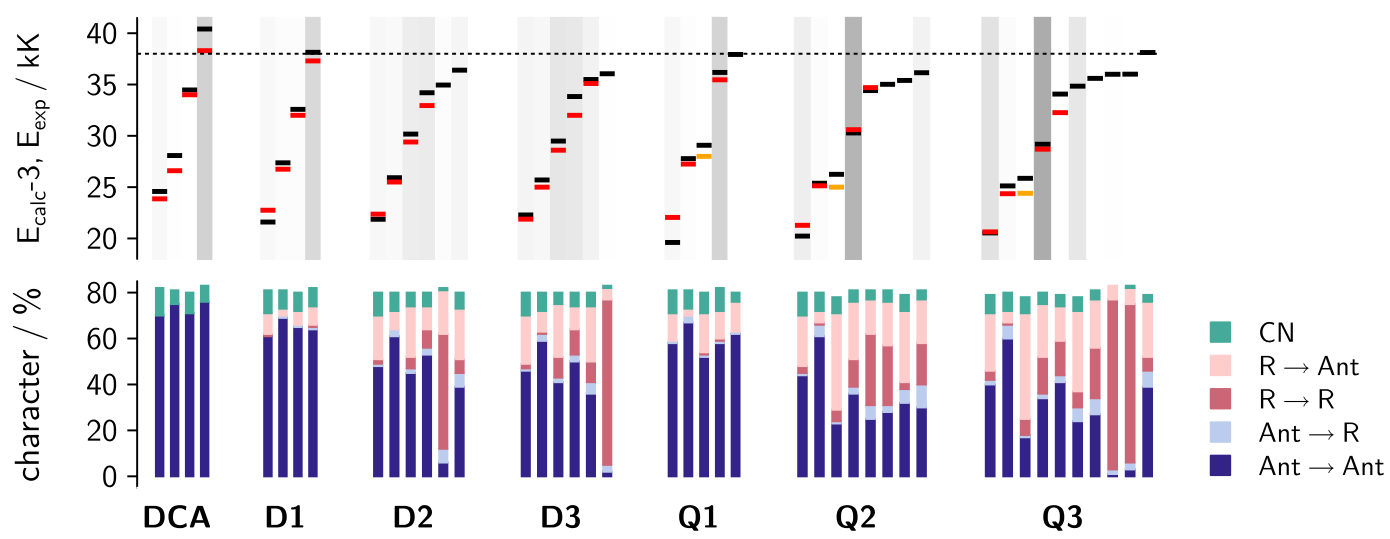

Fig. 8 Upper panel: Comparison of experimental (1P - red lines, 2P - orange lines) and calculated (black lines, vertical excitations red-shifted by $3 \mathrm{kK}$ ) band origins in cyclohexane. The contrast of the background is proportional to the calculated square of the transition dipole moment for absorption. The dashed line indicates the upper limit of the spectral range shown in Figure 6. Lower panel: decomposition of the associated transition into individual local and charge transfer contributions.

X. Fang, S.-J. Jeon and B. R. Cho, Chem. - A Eur. J., 2005, 11, 4191-4198.

23 S. K. Lee, W. J. Yang, J. J. Choi, C. H. Kim, S.-J. Jeon and B. R. Cho, Org. Lett., 2005, 7, 323-326.

24 Q. Zhang, H. Kuwabara, W. J. Potscavage, S. Huang, Y. Hatae, T. Shibata and C. Adachi, J. Am. Chem. Soc., 2014, 136, 18070-18081.

25 J. Choi, D.-S. Ahn, K. Y. Oang, D. W. Cho and H. Ihee, J. Phys. Chem. C, 2017, 121, 24317-24323.

26 Z. Kuang, G. He, H. Song, X. Wang, Z. Hu, H. Sun, Y. Wan, Q. Guo and A. Xia, J. Phys. Chem. C, 2018, 122, 3727-3737.

27 S. Montanaro, A. J. Gillett, S. Feldmann, E. W. Evans, F. Plasser, R. H. Friend and I. A. Wright, Phys. Chem. Chem. Phys., 2019, DOI: 10.1039/C9CP02186H.

28 F. Glöcklhofer, M. Lunzer and J. Fröhlich, Synlett, 2015, 26, 950-952.

29 F. Glöcklhofer, M. Lunzer, B. Stöger and J. Fröhlich, Chem. Eur. J., 2016, 22, 5173-5180.

30 K. W. Rosenmund and E. Struck, Ber. Dtsch. Chem. Ges., 1919, 52, 1749-1756.

31 J. v. Braun and G. Manz, Justus Liebigs Ann. Chem., 1931, 488, 111-126.

32 F. Glöcklhofer, A. J. Morawietz, B. Stöger, M. M. Unterlass and J. Fröhlich, ACS Omega, 2017, 2, 1594-1600.

33 F. Glöcklhofer, P. Kautny, P. Fritz, B. Stöger and J. Fröhlich, ChemPhotoChem, 2016, 1, 51-55.

34 H. Leonhardt and A. Weller, Ber Bunsenges Phys Chem, 1963, 67, 791-795.

35 A. Dreuw and M. Wormit, Wiley Interdiscip. Rev. Comput. Mol. Sci., 2015, 5, 82-95.

36 Y. Shao, Z. Gan, E. Epifanovsky, A. T. Gilbert, M. Wormit, J. Kussmann, A. W. Lange, A. Behn, J. Deng, X. Feng, D. Ghosh, M. Goldey, P. R. Horn, L. D. Jacobson, I. Kaliman, R. Z. Khaliullin, T. Kus, A. Landau, J. Liu, E. I. Proynov, Y. M. Rhee, R. M. Richard, M. A. Rohrdanz, R. P. Steele, E. J. Sund- strom, H. L. Woodcock, P. M. Zimmerman, D. Zuev, B. Albrecht, E. Alguire, B. Austin, G. J. Beran, Y. A. Bernard, E. Berquist, K. Brandhorst, K. B. Bravaya, S. T. Brown, D. Casanova, C. M. Chang, Y. Chen, S. H. Chien, K. D. Closser, D. L. Crittenden, M. Diedenhofen, R. A. Distasio, H. Do, A. D. Dutoi, R. G. Edgar, S. Fatehi, L. Fusti-Molnar, A. Ghysels, A. Golubeva-Zadorozhnaya, J. Gomes, M. W. Hanson-Heine, P. H. Harbach, A. W. Hauser, E. G. Hohenstein, Z. C. Holden, T. C. Jagau, H. Ji, B. Kaduk, K. Khistyaev, J. Kim, J. Kim, R. A. King, P. Klunzinger, D. Kosenkov, T. Kowalczyk, C. M. Krauter, K. U. Lao, A. D. Laurent, K. V. Lawler, S. V. Levchenko, C. Y. Lin, F. Liu, E. Livshits, R. C. Lochan, A. Luenser, P. Manohar, S. F. Manzer, S. P. Mao, N. Mardirossian, A. V. Marenich, S. A. Maurer, N. J. Mayhall, E. Neuscamman, C. M. Oana, R. Olivares-Amaya, D. P. Oneill, J. A. Parkhill, T. M. Perrine, R. Peverati, A. Prociuk, D. R. Rehn, E. Rosta, N. J. Russ, S. M. Sharada, S. Sharma, D. W. Small, A. Sodt, T. Stein, D. Stück, Y. C. Su, A. J. Thom, T. Tsuchimochi, V. Vanovschi, L. Vogt, O. Vydrov, T. Wang, M. A. Watson, J. Wenzel, A. White, C. F. Williams, J. Yang, S. Yeganeh, S. R. Yost, Z. Q. You, I. Y. Zhang, X. Zhang, Y. Zhao, B. R. Brooks, G. K. Chan, D. M. Chipman, C. J. Cramer, W. A. Goddard, M. S. Gordon, W. J. Hehre, A. Klamt, H. F. Schaefer, M. W. Schmidt, C. D. Sherrill, D. G. Truhlar, A. Warshel, X. Xu, A. Aspuru-Guzik, R. Baer, A. T. Bell, N. A. Besley, J. D. Chai, A. Dreuw, B. D. Dunietz, T. R. Furlani, S. R. Gwaltney, C. P. Hsu, Y. Jung, J. Kong, D. S. Lambrecht, W. Liang, C. Ochsenfeld, V. A. Rassolov, L. V. Slipchenko, J. E. Subotnik, T. Van Voorhis, J. M. Herbert, A. I. Krylov, P. M. Gill and M. Head-Gordon, Mol. Phys., 2015, 113, 184-215.

37 S. Knippenberg, D. R. Rehn, M. Wormit, J. H. Starcke, I. L. Rusakova, A. B. Trofimov and A. Dreuw, J. Chem. Phys., 2012, 136, 064107.

38 M. Wormit, D. R. Rehn, P. H. Harbach, J. Wenzel, C. M. Krauter, E. Epifanovsky and A. Dreuw, Mol. Phys., 2014, 112, 774-784. 
39 F. Plasser and H. Lischka, J. Chem. Theory Comput., 2012, 8, 2777-2789.

40 F. Plasser, M. Wormit and A. Dreuw, J. Chem. Phys., 2014, 141, 0-13.

41 B. Dick and G. Hohlneicher, Chem. Phys. Lett., 1981, 83, 615621.

42 I. B. Berlman, Handbook of Fluorescence Spectra of Aromatic Molecules, Academic Press Inc, New York, 2nd edn., 1971.

43 J. B. Birks, Photophysics of Aromatic Molecules, WileyInterscience, 1970.

44 D. Toptygin, J. Flu., 2003, 13, 201-219.

45 A. Kapturkiewicz, J. Herbich, J. Karpiuk and J. Nowacki, J. Phys. Chem. A, 1997, 101, 2332-2344.

46 Z. Li, A. Rosspeintner, P. Hu, G. Zhu, Y. Hu, X. Xiong, R. Peng, M. Wang, X. Liu and R. Liu, Polym. Chem., 2017, 8, 66446653.

47 P. Suppan, J. Photochem. Photobiol., A, 1990, 50, 293-330.

48 N. Ghoneim and P. Suppan, Spectrochim. Acta, Part A, 1995, 51, 1043-1050.

49 L. Onsager, J. Am. Chem. Soc., 1936, 58, 1486-1493.

50 A. J. Dekker, Physica, 1946, 12, 209-216.

51 F. Terenziani, A. Painelli, C. Katan, M. Charlot and M. Blanchard-Desce, J. Am. Chem. Soc., 2006, 128, 1574215755.

52 B. Dereka, A. Rosspeintner, Z. Li, R. Liska and E. Vauthey, J. Am. Chem. Soc., 2016, 138, 4643-4649.

53 P. R. Salvi, Chem. Phys. Lett., 1985, 116, 279-285.

54 M. Klessinger and J. Michl, Excited States and Photochemistry of Organic Molecules, VCH, 1995.

55 A. J. Aquino, H. Lischka and C. Hättig, J. Phys. Chem. A, 2005, 109, 3201-3208.

56 B. Le Guennic, G. Scalmani, M. J. Frisch, A. D. Laurent and D. Jacquemin, Phys. Chem. Chem. Phys., 2017, 19, 1055410561.

57 P. H. Harbach, M. Wormit and A. Dreuw, J. Chem. Phys., 2014, $141,1-34$. 